ISSN 0103-9954

\title{
SUBSTRATOS E NÍVEIS DE LUMINOSIDADE NO CRESCIMENTO INICIAL DE MUDAS DE Tocoyena formosa (Cham. \& Schltdl.) K. Schum. (RUBIACEAE)
}

\author{
SUBSTRATES AND LEVELS OF LIGHT INTENSITY ON INITIAL GROWTH OF SEEDLINGS OF \\ Tocoyena formosa (Cham. \& Schltdl.) K. Schum. (RUBIACEAE)
}

Thaliny Bonamigo ${ }^{1}$ Silvana de Paula Quintão Scalon ${ }^{2}$ Zefa Valdivina Pereira ${ }^{3}$

\begin{abstract}
RESUMO
Objetivou-se determinar o tipo de substrato e as melhores condições de luminosidade para o cultivo de mudas de Tocoyena formosa (Cham. \& Schltdl.) K. Schum. A semeadura ocorreu em bandejas de isopor sob sombrite de $70 \%$ e três meses após a emergência, as plântulas foram selecionadas e em seguida transplantadas em vasos de $4 \mathrm{~L}$, em dois tipos de substratos: 50\% de solo Latossolo Vermelho Distroférrico $+50 \%$ de areia (TA) e 50\% de solo de Latossolo Vermelho Distroférrico $+25 \%$ de areia $+25 \%$ de cama de frango semidecomposta (TACF). Após o transplante, as mudas foram levadas para três condições de sombreamento $(30 \%, 50 \%$ e $70 \%$ de sombra $)$ e a pleno sol ( $0 \%)$. Após a aclimatação, a qualidade siológica das mudas foi determinada mensalmente, através da análise de crescimento e do índice de qualidade de Dickson, durante 90 dias. O experimento foi realizado em DIC em esquema fatorial 2 x 4 x 4 (substratos $\mathrm{x}$ sombreamento $\mathrm{x}$ idade da muda), com três repetições de três mudas. Foi observado maior crescimento e qualidade das mudas em substrato terra + areia + cama de frango e nas condições de $30 \%$ de sombra e pleno sol. Conclui-se que para produção de mudas de Tocoyena formosa a melhor condição de luminosidade é $30 \%$ de sombra e em pleno sol em substrato TACF.
\end{abstract}

Palavras-chave: luz; Cerrado; jenipapo-bravo; produção de mudas.

\begin{abstract}
The aim of this study was to determine the best substrate type and light conditions for the cultivation of seedlings of Tocoyena formosa (Cham. \& Schltdl.) K. Schum. Seeds were planted in Styrofoam trays under $70 \%$ shading. Three months after emergence, the seedlings were selected and transplanted in 4-L pots, in two types of substrates: 50\% dystroferric Red Latosol $+50 \%$ sand (TA) and 50\% dystroferric Red Latosol + $25 \%$ sand $+25 \%$ semi-decomposed chicken manure (TACF). After transplanting, the seedlings were placed under three conditions of shading (30,50 and 70\% shade) and full sun ( $0 \%$ shade). After acclimation, the physiologic quality of the seedlings was determined monthly, by analysis of growth and Dickson quality index, for 90 days. The experiment was carried out using a randomized block design in a $2 \mathrm{x} 4 \mathrm{x} 4$ factorial scheme (substrate $\mathrm{x}$ shading $\mathrm{x}$ age of seedling), with three repetitions of three seedlings. There was greater growth and quality of the seedlings in the substrate soil + sand + chicken manure and under conditions of $30 \%$ shade and full sun. It is concluded that for the production of seedlings of Tocoyena formosa, the best conditions are $30 \%$ shade and full sun for light and TACF for substrate.
\end{abstract}

Keywords: light; Cerrado; jenipapo-bravo; production of seedlings.

1 Bióloga, MSc., Doutoranda em Biotecnologia e Biodiversidade, Universidade Federal da Grande Dourados, Rod. Dourados - Itahum, Km 12, Caixa Postal 533, Cidade Universitária, CEP 79804-970, Dourados (MS), Brasil. thalibonamigo@hotmail.com

2 Bióloga, Dra ${ }^{\mathrm{a}}$, Professora Associada da Faculdade de Ciências Agrárias, Universidade Federal da Grande Dourados, Rod. Dourados - Itahum, Km 12, Caixa Postal 533, Cidade Universitária, CEP 79804-970, Dourados (MS), Brasil. Bolsista de Produtividade CNPQ. silvanascalon@ufgd.edu.br

3 Bióloga, Dr ${ }^{\mathrm{a}}$., Professora Adjunta da Faculdade de Ciências Biológicas e Ambientais, Universidade Federal da Grande Dourados, Rod. Dourados - Itahum, Km 12, Caixa Postal 533, Cidade Universitária, CEP 79804-970, Dourados (MS), Brasil. zefapereira@ufgd.edu.br

Recebido para publicação em 15/10/2013 e aceito em 10/09/2014

Ci. Fl., v. 26, n. 2, abr.-jun., 2016 


\section{INTRODUÇÃO}

Tocoyena formosa (Cham. \& Schltdl.) K. Schum., conhecida popularmente como jenipapo-bravo, é uma espécie lenhosa de porte arbustivo-arbóreo ocorrente no Cerrado brasileiro (GOTTSBERGER; EHRENDORFER, 1992), que possui potencial de uso madeireiro, ornamental (RONDON-NETO et al., 2010), medicinal (COELHO; AGRA; BARBOSA, 2006) e pode servir como componente eventual da dieta de bovinos (POTT, 1982). Ainda não foram encontradas informações relacionadas à germinação, cultivo e desenvolvimento desta espécie, que em algumas regiões do Brasil já se encontra em extinção (VIEIRA; LIMA; CAMPOS, 2010).

Segundo Dantas et al. (2009), os fatores ambientais que mais influenciam na produção de mudas são: o substrato e a luminosidade. Espécies arbóreas apresentam respostas variadas em relação à alteração na disponibilidade de luz. Para enfrentar as adversidades luminosas do ambiente, as plantas possuem adaptações que envolvem o ajuste de seu aparelho fotossintético, com finalidade de utilizar a luz de maneira mais eficiente possível, porém, tal eficiência varia conforme as espécies e é refletida no crescimento global da planta. Assim, como consequências da alteração da luminosidade são frequentemente observadas variações na razão clorofila $\mathrm{a} / \mathrm{b}$, espessura foliar, teor de nitrogênio, densidade estomática, e/ou alterações na proporção de tecidos fotossintetizantes em relação aos não fotossintetizantes, levando à modificação na distribuição de biomassa (MATOS et al., 2011; FREITAS et al., 2012). Deste modo, estas características do crescimento são utilizadas para predizer o grau de tolerância das diferentes espécies ao sombreamento, como pode ser verificado nos trabalhos de Lima et al. (2008) e Ferreira et al. (2012).

O tipo de substrato utilizado na produção de mudas desempenha funções importantes, como o suporte das raízes das plantas e o fornecimento de água, oxigênio e nutrientes para que a parte aérea se desenvolva (FACHINI; GALBIATTI; PAVANI, 2004). Além disso, as propriedades biológicas, que englobam os micro-organismos existentes no solo, podem influenciar diretamente suas características físicas e químicas, como aeração, retenção de água, disponibilidade de alguns nutrientes, entre outras, refletindo no crescimento e desenvolvimento da planta (KÄMPF, 2001). A adição de resíduos orgânicos, como por exemplo, cama de frango, esterco de vaca, bagaço de cana e resíduos domésticos urbanos podem melhorar a textura do substrato, de maneira a fornecer boas condições físicas e químicas ao desenvolvimento das raízes e parte aérea (FACHINI; GALBIATTI; PAVANI, 2004; SEVERINO; LIMA; BELTRÃO, 2006; DANTAS et al., 2009).

Assim, o conhecimento sobre as necessidades de luz e substratos de uma espécie arbórea poderá subsidiar e estimular sua propagação com finalidades de recomposição de florestas ou desenvolvimento de plantações de espécies economicamente importantes para fins de exploração sustentável. Portanto, o objetivo deste trabalho foi avaliar a influência do sombreamento e do substrato no crescimento de mudas de Tocoyena formosa.

\section{MATERIAL E MÉTODOS}

O experimento foi desenvolvido na Universidade Federal da Grande Dourados (UFGD), localizada no estado do Mato Grosso do Sul, Brasil.

Os frutos de Tocoyena formosa foram colhidos a partir de oito matrizes, aleatórias, em áreas remanescentes de Cerrado na rodovia BR 267 (Coordenadas 2139'11,8"S e 56 36'1,6"W) que liga o município de Bonito a Jardim, Mato Grosso do Sul. Após a coleta, os frutos foram despolpados manualmente para a retirada das sementes, que foram lavadas em água corrente e secas à sombra por 24 horas, e, em seguida, foram semeadas em bandejas de isopor, com 128 células, contendo como substrato Bioplant ${ }^{\circledR}$ e colocadas sob sombrite $70 \%$.

Aos três meses, após a emergência, foram selecionadas mudas, em média, com $10 \mathrm{~cm}$ de tamanho, que foram transplantadas em vasos de $4 \mathrm{~L}$, em dois tipos de substratos: $50 \%$ de solo Latossolo Vermelho Distroférrico $+50 \%$ de areia (TA) e 50\% de solo de Latossolo Vermelho Distroférrico $+25 \%$ de areia $+25 \%$ de cama de frango semidecomposta (TACF). O Latossolo Vermelho Distroférrico foi coletado na camada superficial $(0-20 \mathrm{~cm}$ de profundidade). Foram utilizadas quatro amostras, de cada substrato, para a análise física e química (Tabela 1), segundo Embrapa (1997). A análise física dos substratos foi relativamente semelhante, os substratos contendo areia + terra e o contendo terra + areia + cama de frango, apresentaram 587,02 e $588,15 \mathrm{~g} \mathrm{~kg}^{-1}$ de areia, 337,66 e $320,56 \mathrm{~g} \mathrm{~kg}^{-1} \mathrm{de}$ argila, 75,30 e $92,78 \mathrm{~g} \mathrm{~kg}^{-1}$ de silte, 1,33 e $1,13 \mathrm{~g} /$ 
TABELA 1: Análise química ${ }^{1}$ dos diferentes substratos. Dourados - MS, UFGD, 2013.

TABLE 1: Chemistry analysis ${ }^{1}$ of different substrates. Dourados - MS, UFGD, 2013.

\begin{tabular}{|c|c|c|c|c|c|c|c|c|c|c|c|c|c|c|c|}
\hline \multirow{2}{*}{ Substrato } & $\mathrm{pH}$ & $\mathrm{pH}$ & $\mathrm{P}$ & $\mathrm{K}$ & $\mathrm{Al}$ & SB & $\mathrm{T}$ & $\mathrm{Ca}$ & $\mathrm{Mg}$ & $\mathrm{H}+\mathrm{Al}$ & $\mathrm{Cu}$ & $\mathrm{Mn}$ & $\mathrm{Zn}$ & $\mathrm{Fe}$ & $\mathrm{V}$ \\
\hline & SMP & $\mathrm{CaCl}_{2}$ & $\left(\mathrm{mg} / \mathrm{dm}^{3}\right)$ & \multicolumn{4}{|c|}{-----mmol----- } & \multicolumn{3}{|c|}{---------cmol-------- } & \multicolumn{4}{|c|}{-----(mg/dm³ $\left.{ }^{3}\right)-----$} & $\%$ \\
\hline TA & 7,0 & 5,7 & 2,7 & 1,0 & 0,0 & 57,6 & 76,4 & 2,8 & 1,8 & 1,9 & 6,6 & 40,9 & 1,5 & 157,6 & 75,0 \\
\hline TACF & 7,3 & 6,3 & 197,7 & 2,8 & 0,0 & 95,6 & 109,2 & 4,6 & 4,6 & 1,4 & 10,3 & 77,1 & 22,69 & 52,8 & 87,0 \\
\hline
\end{tabular}

Em que: TA-50\% de solo de Latossolo Vermelho Distroférrico natural da região $+50 \%$ de areia. TACF-50\% de solo de Latossolo Vermelho Distroférrico natural da região $+25 \%$ de areia $+25 \%$ de cama de frango semidecomposta.

$\mathrm{cm}^{3}$ de densidade aparente 2,70 e $2,74 \mathrm{~g} / \mathrm{cm}^{3}$ de densidade real e 50,56 e $58,67 \%$ de porosidade, respectivamente.

Quarenta e cinco dias após o transplante, as mudas foram levadas para três condições de sombreamento $(30 \%, 50 \%$ e $70 \%$ de sombra) e a pleno sol $(0 \%)$, nas quais permaneceram por mais 45 dias para a aclimatação, sendo irrigadas diariamente, mantendo-se a capacidade de campo em aproximadamente $60 \%$ (SOUZA et al., 2000).

Após o período de aclimatação, quando as mudas se encontravam com 180 dias de idade e a cada 30 dias até as mudas completarem 270 dias de idade, foi determinada a qualidade fisiológica das plantas avaliando-se, mensalmente, o crescimento das mudas pelas seguintes medições: comprimento de raiz e parte aérea, massa seca de raiz e parte aérea, razão entre comprimento da parte aérea (CPA) e massa seca da parte aérea (MSPA) (BERNARDINO et al., 2005), diâmetro do colo, com auxílio de paquímetro digital, número de folhas, área foliar, com auxílio de integrador de área foliar LI-COR 3100, índice de clorofila, utilizando SPAD 502 e índice de qualidade de Dickson (IQD), segundo a metodologia utilizada por Dickson, Leaf e Hosner (1960).

O delineamento experimental utilizado foi $\mathrm{o}$ inteiramente casualizado em esquema fatorial $4 \mathrm{x}$ $2 \times 4$ (sombreamento $x$ substrato $x$ idade da muda), com três repetições de três mudas, para cada época, totalizando 288 mudas.

Os resultados foram submetidos à análise de variância e havendo diferença significativa as médias de sombreamento e substratos foram comparados pelo teste de Tukey e as médias de idade da muda e sua interação com os outros fatores foram ajustadas por regressão, ambos a 5\% de significância, com o uso do programa SISVAR (FERREIRA, 2000).

\section{RESULTADOS E DISCUSSÃO}

Não houve interação tripla para nenhuma das características avaliadas. Houve interação entre os níveis de sombreamento e idade da muda (IM) somente sobre a área foliar (AF) e massa seca de raiz (MSR), e parte aérea (MSPA); interação entre substrato e idade da muda somente sobre o comprimento de parte aérea (CPA), número de folhas (NF), índice de clorofila (IC), diâmetro do colo (DC), AF, MSR, MSPA e índice de qualidade de Dickson (IQD), e interação entre o substrato e os níveis de sombreamento sobre o CPA, NF, MSR e MSPA. Houve efeito significativo dos níveis de sombreamento sobre o DC, IC e IQD, e das diferentes idades da muda sobre o CR.

$\mathrm{O}$ crescimento radicular aumentou com a idade da muda (Figura 1a). Para o comprimento da parte aérea foi observado maior crescimento quando em condições de $30 \%$ de sombra e em substrato contendo composto orgânico (Figuras $1 b$ e 1d). Neste contexto, embora o maior sombreamento pudesse proporcionar o estiolamento das mudas, esse fato não aconteceu para Tocoyena formosa. Nas condições de 50 e $70 \%$ de sombreamento, o CPA nos diferentes substratos não apresentou diferença estatística, isso pode estar associado à maior disponibilidade de umidade do ambiente nestas condições, uma vez que, em condições de maior sombreamento, a temperatura ambiente pode ser bem menor, levando à menor taxa de transpiração das folhas (PIEREZAN; SCALON; PEREIRA, 2012) suprindo as necessidades das plantas. Estas condições de maior sombreamento proporcionaram crescimento semelhante de várias características avaliadas neste trabalho.

$\mathrm{O}$ diâmetro do colo foi maior quando em substrato contendo terra + areia + cama de frango (Figura 1b) e em maiores níveis de luminosidade 

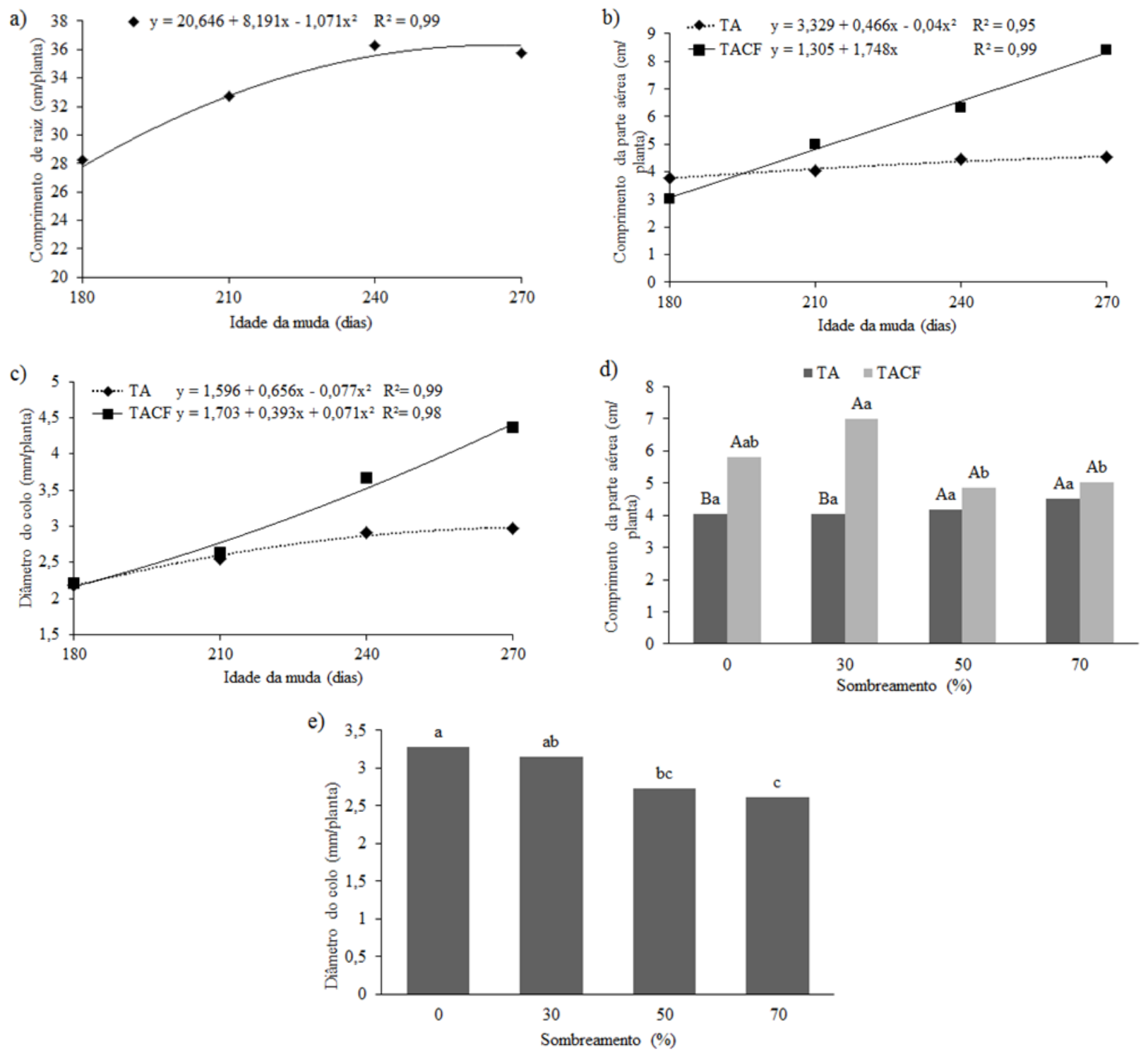

FIGURA 1: Comprimento da raiz (a), parte aérea (b, d) e diâmetro do colo (c, e) das mudas de Tocoyena formosa produzidas em diferentes substratos e sombreamentos. Dourados - MS, UFGD, 2013. Letras maiúsculas comparam diferentes substratos para o mesmo sombreamento (Teste F) (d) e letras minúsculas comparam diferentes sombreamentos para o mesmo substrato (d) (Teste de Tukey) (c) ou diferentes sombreamentos (e) a $5 \%$ de probabilidade.

FIGURE 1: Length of root (a) and of shoot part (b, d) and stem diameter (c, e) of the seedlings of Tocoyena formosa produced with different substrates and shadings. Dourados - MS, UFGD, 2013. Uppercase letters compare different substrates for the same shading (F test) (d) and lowercase letters compare different shadings for the same substrate (d) (Tukey test) (c) or different shadings (e) at $5 \%$ probability.

(pleno sol e 30\% de sombreamento) (Figura 1d), quando comparada com plantas cultivadas em 50 e $70 \%$ de sombreamento, as quais apresentaram menor DC (2,71 e 2,61 $\mathrm{mm}$ respectivamente) aos 270 dias.

Muitos dados experimentais citados na literatura mostram que o aumento do nível de luminosidade influencia na divisão, no crescimento e na diferenciação celular, promovendo o alongamento das células e produção de pigmentos e açúcares (SANTIAGO et al., 2001). Portanto, o aumento da luminosidade e da quantidade de nutrientes do substrato, fornecido pela cama de frango, favoreceu a produção de biomassa das 
mudas de Tocoyena formosa.

As mudas, inicialmente, desenvolveramse em ambiente com baixa luminosidade $(70 \%$ de sombra) e, posteriormente, foram transferidas para níveis mais elevados de luz (50 e 30\% de sombra) e pleno sol. Com essa mudança, as plantas responderam à irradiância, aumentando a massa seca de raiz e parte aérea, a área foliar, o número de folhas e distribuição de biomassa para a raiz, assim como foi observado em estudos de Nakazono et al. (2001) com plantas de palmito-juçara (Euterpe edulis Mart.) transferidas de baixa (4\% de luz solar direta) para maior luminosidade $(20 \%$ ou $30 \%$ de luz).

No entanto, segundo Walters e Reich (2000), a tolerância ao sombreamento nem sempre envolve um aumento na capacidade fisiológica de crescer com pouca luz, visto que grandes potenciais de crescimento podem resultar em maior reposição de tecidos, maiores taxas respiratórias, maiores danos mecânicos por herbivoria e menor estocagem de fotoassimilados.

$\mathrm{O}$ maior crescimento da parte aérea no substrato TACF pode estar relacionado com a maior quantidade de nutrientes encontrados neste tipo de substrato (Tabela 1), ou, em função da adição de matéria orgânica, houve maior retenção e disponibilidade de água para manter a turgescência e metabolismo da parte aérea. Lavres-Júnior et al. (2005) sugerem que a falta de nutrientes pode comprometer o desenvolvimento das plantas e dentre os sintomas estão o menor crescimento da parte aérea.

Segundo Larcher (2006), o crescimento em diâmetro apresenta relação direta com a fotossíntese líquida a qual depende, entre outros fatores, de um balanço favorável entre fotossíntese líquida e respiração. Deste modo, em maior luminosidade há maior atividade fotossintética das plantas favorecendo o crescimento do diâmetro do colo. Assim como no presente estudo, foram observados maiores diâmetros do colo, sob maiores níveis de luminosidade, em espécies como jequitibá-rosa (Cariniana legalis (Martius) Kuntze) (REGO; PASSAMAI, 2006) e mutambo (Guazuma ulmifolia L.) (SCALON et al., 2011).

Os resultados do comprimento de raiz evidenciam que não houve aumento do comprimento da raiz nos diferentes tratamentos, no entanto, observou-se que as plantas cultivadas em substrato TACF, apresentaram maior massa seca de raiz. As plantas cultivadas em substrato TACF e em sombreamento de 30\% (Figura 2c) apresentaram maior massa seca de raiz, no entanto, não foi verificada diferença significativa entre os substratos a $70 \%$ de sombreamento, provavelmente, devido à maior disponibilidade de umidade para o sistema radicular.

Em relação à matéria seca da parte aérea, esta foi maior nos maiores níveis de luminosidade (pleno sol e 30\% de sombra) (Figuras $2 \mathrm{~b}$ e $2 \mathrm{f}$ ) e no substrato TACF, com exceção do sombreamento de $70 \%$ (Figura 2d).

A maior massa seca de raiz encontrada no substrato TACF e nos maiores níveis de luz pode propiciar um melhor desempenho das mudas no campo, especialmente em áreas degradadas, pois a sobrevivência e qualidade da planta vão ser maiores, em razão da maior facilidade de sustentação e maior área para absorção de água e nutrientes. Scalon et al. (2011) também observaram que mudas de mutambo crescidas em pleno sol apresentaram maior massa seca da parte aérea quando comparadas às cultivadas em sombreamento, assim como as mudas de angico (Anadenanthera peregrina L.) cultivadas por Nóbrega et al. (2008) em presença de composto orgânico apresentaram maior altura da parte aérea e da massa seca de raiz e parte aérea.

A razão entre o comprimento de parte aérea e a massa seca da parte aérea reduziu com o aumento da idade da muda e houve uma queda na relação $\mathrm{CPA} / \mathrm{MSPA}$, demonstrando o aumento da rusticidade conforme o crescimento da planta principalmente se cultivada no substrato TACF (Figura 3).

A razão entre o comprimento de parte aérea e a massa seca da parte aérea é uma variável importante, pois prediz o potencial de sobrevivência de plantas no campo (BERNARDINHO et al., 2005). Quanto menor o coeficiente obtido, maior quantidade de lignina terá a muda, consequentemente maior será sua rusticidade e suas chances de sobrevivência (LUCA; REBECCHI; SCHORN, 2010). Os dados obtidos nesse trabalho estão de acordo com Nóbrega et al. (2008), os quais observaram que em substrato sem adição de compostos orgânicos, a relação CPA/ MSPA de mudas de sesbania (Sesbania virgata (Caz.) Pers) e de Anadenanthera peregrina foi maior.

O número de folhas foi maior nas plantas cultivadas em substrato contendo cama de frango e nas plantas cultivadas em pleno sol (Figuras 

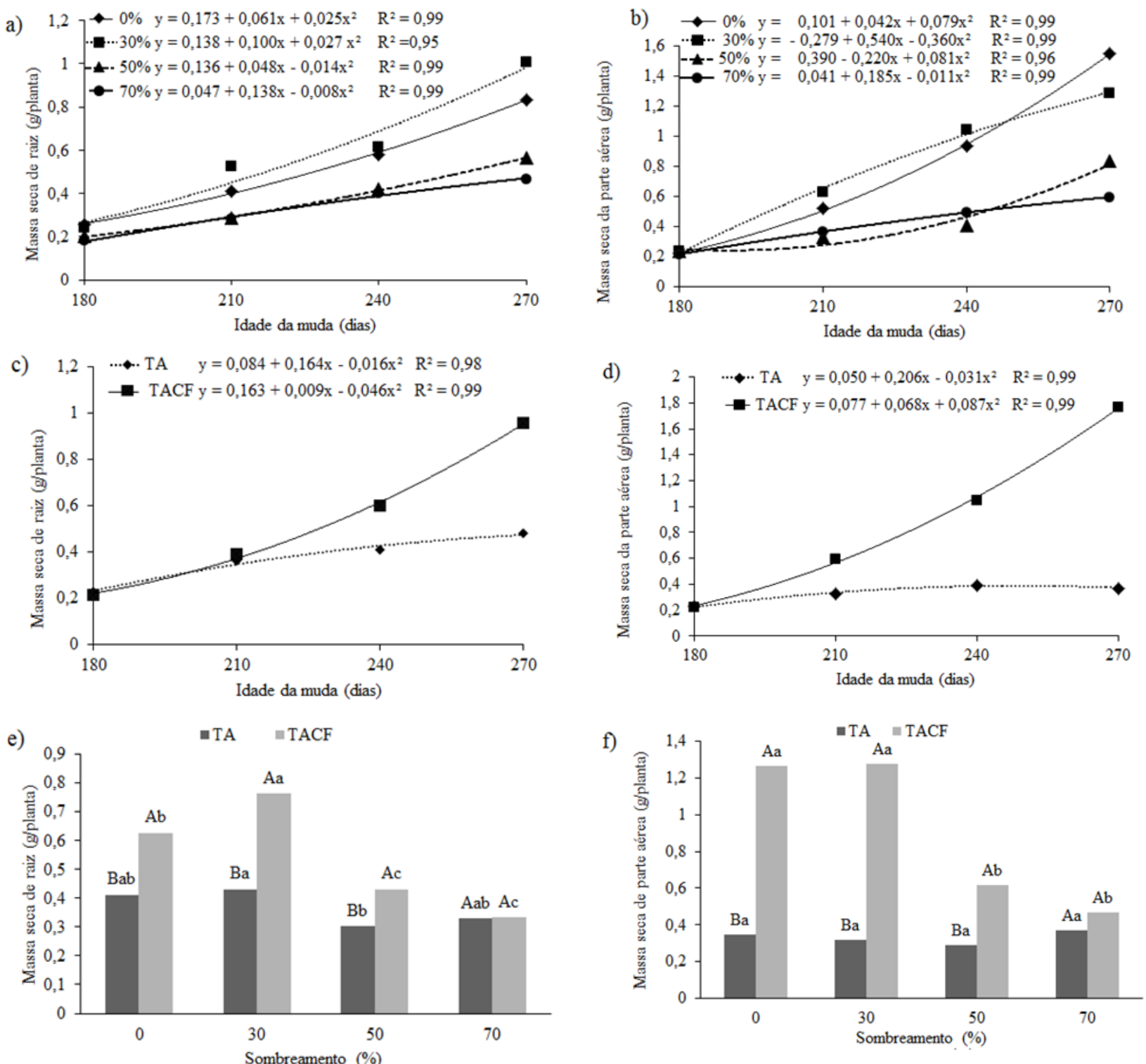

FIGURA 2: Massa seca da raiz (a, c, e) e parte aérea (b, d, f) das mudas de Tocoyena formosa produzidas em diferentes substratos e sombreamentos. Dourados - MS, UFGD, 2013. Letras maiúsculas comparam diferentes substratos para o mesmo sombreamento (Teste F) e letras minúsculas comparam diferentes sombreamentos para o mesmo substrato (Teste de Tukey) (e, f) a 5\% de probabilidade.

FIGURE 2: Dry weight of root (a, c, e) and of shoot part (b, d, f) of the seedlings of Tocoyena formosa produced with different substrates and shadings. Dourados - MS, UFGD, 2013. Uppercase letters compare different substrates for the same shading ( $\mathrm{F}$ test) and lowercase letters compare different shadings for the same substrate (Tukey test) (e, f) at $5 \%$ probability.

4a e 4b). A interação sombreamento x substrato mostrou que plantas cultivadas em pleno sol e $30 \%$ de sombreamento apresentaram maior número de folhas quando em substrato contendo cama de frango. Semelhante as outras características avaliadas, o número de folhas das plantas cultivadas em 50 e $70 \%$ de sombreamento também não diferiram estatisticamente em relação ao substrato.

A área foliar foi maior em menores níveis de sombreamento (Figura 4c). O crescimento da área foliar também foi maior no substrato TACF, e este foi diretamente proporcional ao aumento da luminosidade (Figuras 4d e 4e). Contrariando dados da literatura, que evidenciam que espécies 
a)

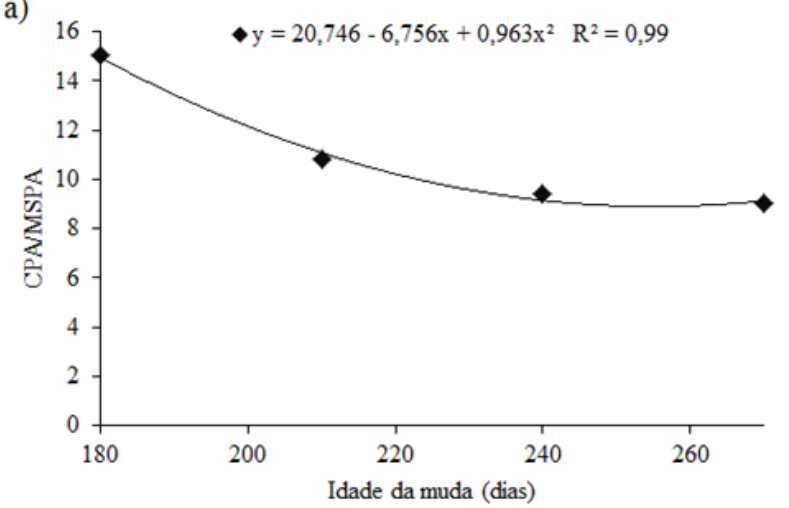

b)

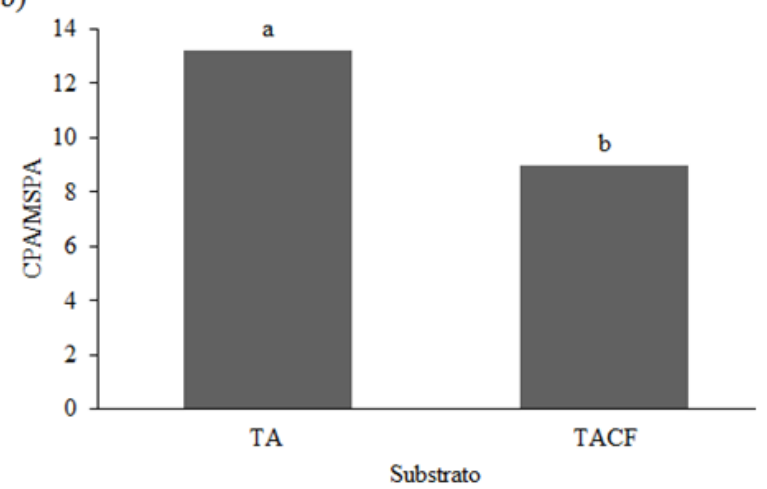

FIGURA 3: Razão entre o comprimento da parte aérea (CPA) e massa seca de parte aérea (MSPA) das mudas de Tocoyena formosa produzidas em diferentes substratos e sombreamento. Dourados - MS, UFGD, 2013. Médias seguidas pelas mesmas letras, não diferem, pelo teste F a 5\% de probabilidade (b).

FIGURE 3: Ratio of length of aerial part (CPA) to dry weight of shoot part (MSPA) of the seedlings of Tocoyena formosa produced with different substrates and shadings. Dourados - MS, UFGD, 2013. Means followed by same letters do not differ by the $\mathrm{F}$ test at $5 \%$ probability (b).

tolerantes ao sombreamento tendem a aumentar a área foliar em condições de baixa radiação solar, Tocoyena formosa teve comportamento semelhante a espécies heliófitas, as quais apresentam aumento da área foliar com a maior luminosidade (DALE, 1988).

O maior crescimento das mudas em substrato TACF pode estar relacionado à maior quantidade de $\mathrm{P}\left(197,7 \mathrm{mg} / \mathrm{dm}^{3}\right)$ e $\mathrm{Ca}(4,6 \mathrm{mg} /$ $\mathrm{dm}^{3}$ ) (Tabela 1) quando comparado ao substrato TA, o qual apresentou $2,7 \mathrm{mg} / \mathrm{dm}^{3}$ de P e $2,6 \mathrm{mg} /$ $\mathrm{dm}^{3} \mathrm{de} \mathrm{Ca}$, sugerindo que esta espécie responde bem à adição de minerais ao substrato. Segundo Melo (1999), o fósforo foi um fator limitante para o crescimento de cagaita (Eugenia dysenterica DC.) (Myrtaceae), veludo (Sclerolobium paniculatum Vog.) (Leguminosae), baru (Dipteryx alata Vog.) (Leguminosae) e mangaba (Hancornia speciosa Gomez) (Apocinaceae), espécies arbóreas do Cerrado. O crescimento do diâmetro do colo, altura da planta, área foliar e número de folhas, foi diretamente proporcional à adição de fósforo e cálcio no solo. $\mathrm{O}$ autor ressalta ainda que a deficiência destes nutrientes no solo pode ser um fator limitante comum para as espécies nativas em solos distróficos do Cerrado.

Além disso, os micronutrientes também possuem grande importância no crescimento e reprodução das plantas. Apesar de serem requeridos em pequenas quantidades, são tão importantes quanto os macronutrientes. Alguns micronutrientes como, $\mathrm{Fe}, \mathrm{Cu}, \mathrm{Mn}$, atuam na fotossíntese, outros como $\mathrm{Zn}$ agem como ativadores de enzimas, sendo requeridos em quantidades adequadas para que possam aumentar a produtividade e qualidade das plantas, conferindo maior resistência a estresses abióticos, bióticos, doenças e pragas (KIRKBY; RÖMHELD, 2007). Nos substratos analisados, a quantidade de micronutrientes avaliados, com exceção do Fe, foi maior no substrato TACF. Isto pode estar relacionado ao melhor desenvolvimento das mudas neste substrato. No substrato TA, foram encontradas elevadas concentrações de $\mathrm{Fe}$, que, segundo Kirkby e Römheld (2007), está relacionado à inibição do crescimento da folhas.

O índice de clorofila das plantas cultivadas em substrato TACF manteve-se maior que o das cultivadas em TA, as quais apresentaram IC decrescente, conforme o aumento da idade da planta (Figura 5a). Em relação ao sombreamento, o índice de clorofila diferiu estatisticamente entre as plantas cultivadas em pleno sol e $70 \%$ de sombreamento, demonstrando maior IC $(29,67)$ em plantas cultivadas a $70 \%$ de sombra (Figura 5c). Além dos parâmetros de crescimento serem maiores no substrato TACF, foi verificado que o índice de qualidade de Dickson das mudas também foi maior neste substrato e em pleno sol e em 30\% de sombreamento (Figura 5).

$\mathrm{O}$ substrato contendo cama de frango apresentou maior quantidade de nutrientes em 

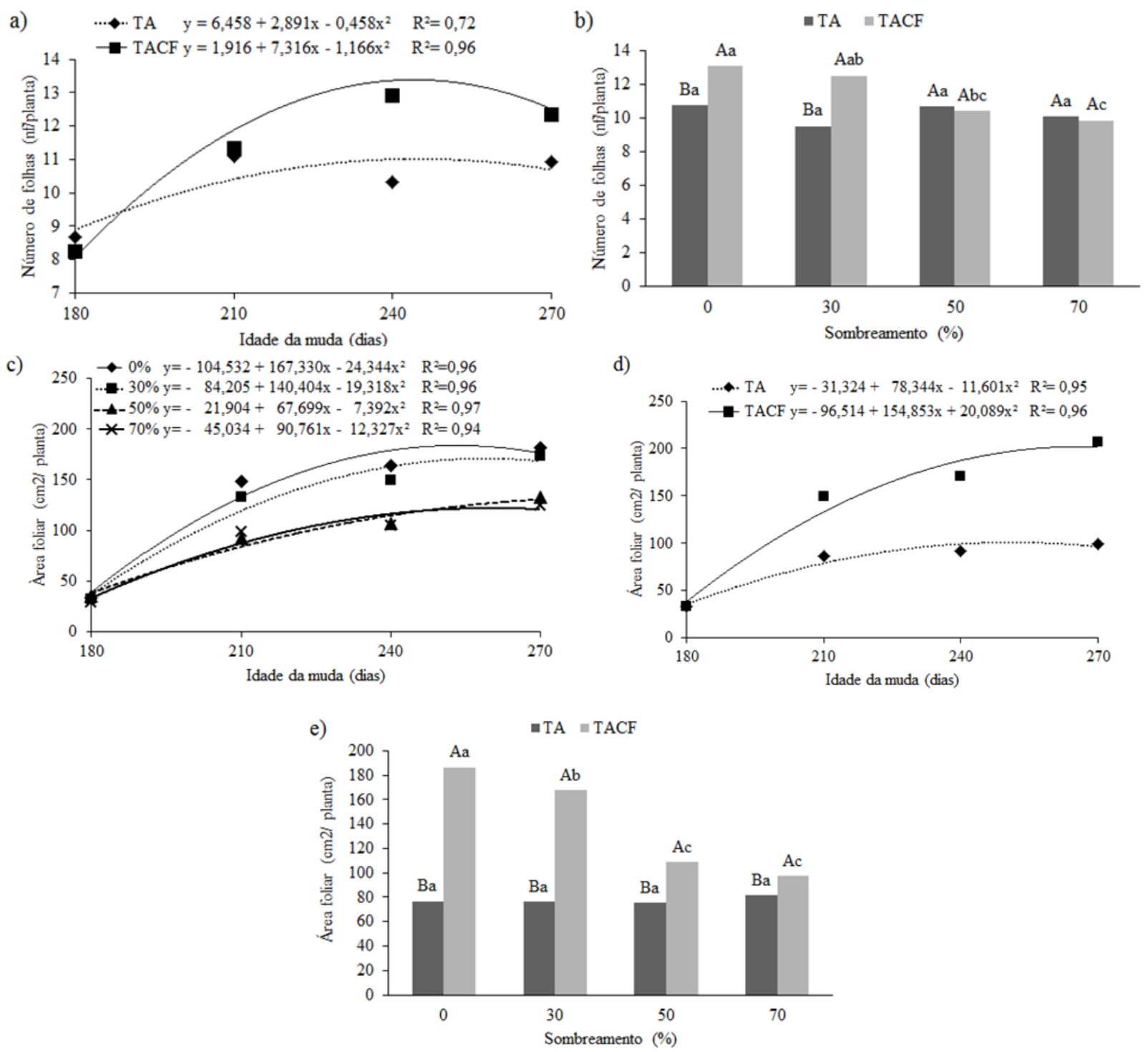

FIGURA 4: Número de folhas (a e b) e área foliar das mudas (c, d, e) de Tocoyena formosa produzidas em diferentes substratos e sombreamentos. Dourados - MS, UFGD, 2013. Letras maiúsculas comparam diferentes substratos para o mesmo sombreamento (Teste F) e letras minúsculas comparam diferentes sombreamentos para o mesmo substrato (Teste de Tukey) (b, e) a 5\% de probabilidade.

FIGURE 4: Number of leaves (a e b) and foliar area of the seedlings (c, d, e) of Tocoyena formosa produced with different substrates and shadings. Dourados - MS, UFGD, 2013. Uppercase letters compare different substrates for the same shading ( $\mathrm{F}$ test) and lowercase letters compare different shadings for the same substrate (Tukey test) (b, e) at $5 \%$ probability.

relação ao TA. Alguns nutrientes como o $\mathrm{Mg}$ e N, participam da formação da clorofila além de outras características que favorecem o crescimento das plantas. Em estudo da análise química de diferentes substratos, Severino, Lima e Beltão (2006) observaram que o substrato contendo cama de frango estava quase sempre relacionado aos maiores índices de nutrientes, como $\mathrm{K}, \mathrm{Mg}, \mathrm{P}$ e $\mathrm{N}$, quando comparado com substratos de esterco bovino, mucilagem de sisal e bagaço de cana e polpa de mamona.

Em relação à luminosidade, o maior índice de clorofila em maior sombreamento pode ser uma característica adaptativa da espécie para maximizar a captura de luz (CRITCHLEY, 1999). Estes resultados estão de acordo com os encontrados 
a)

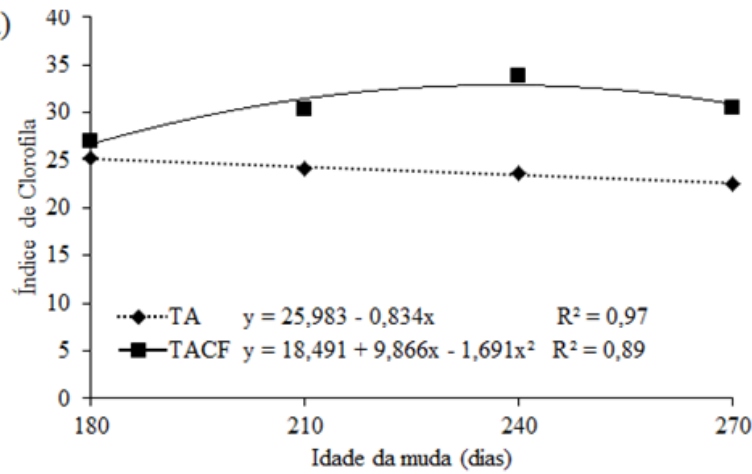

c)

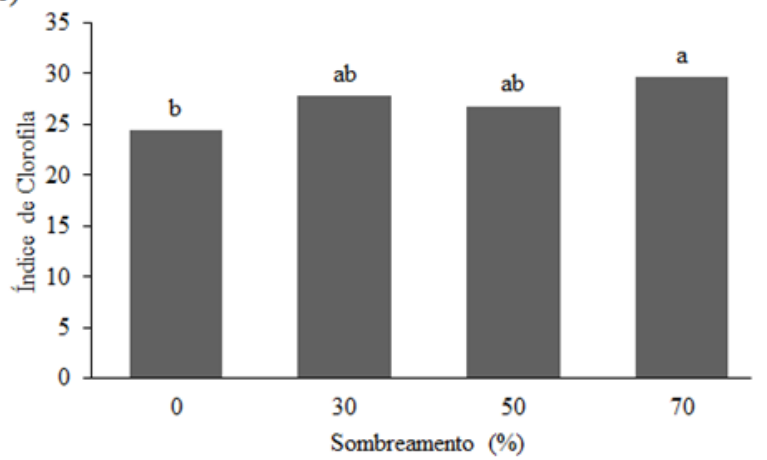

b)

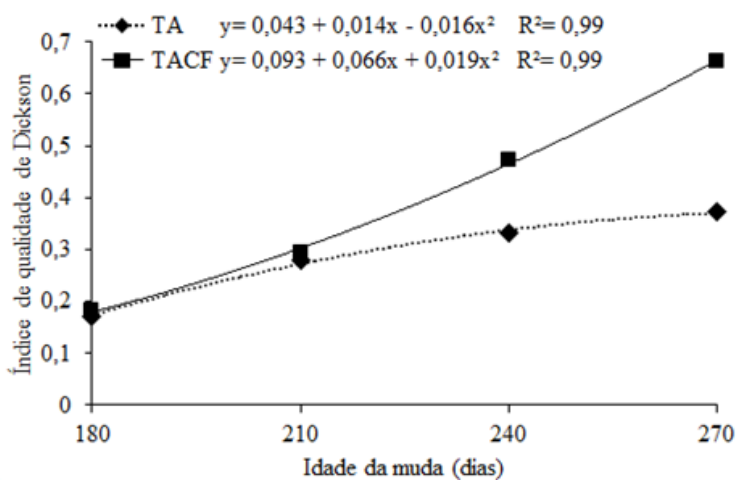

d)

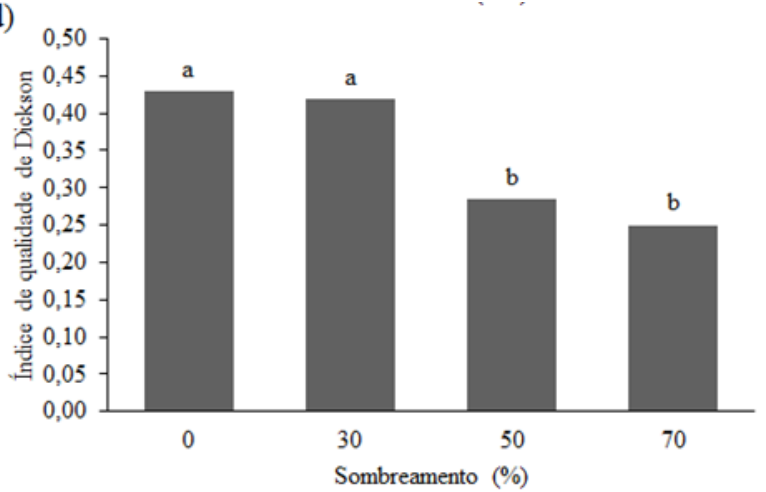

FIGURA 5: Índice de clorofila das mudas (a, c) e índice de qualidade de Dickson (b, d) de Tocoyena formosa produzidas em diferentes substratos e sombreamentos. Dourados - MS, UFGD, 2013. Médias seguidas pelas mesmas letras, não diferem, pelo teste de Tukey a $5 \%$ de probabilidade (c, d).

FIGURE 5: Chlorophyll index of the seedlings (a, c) and Dickson quality index (b, d) of Tocoyena formosa produced with different substrates and shadings. Dourados - MS, UFGD, 2013. Means followed by same letters do not differ by the Tukey test at $5 \%$ probability (c, d).

por Rego e Passamai (2006), os quais observaram que níveis de sombreamento mais elevados proporcionaram maior teor de clorofila total para a espécie arbórea jequitibá-rosa.

O índice de qualidade de Dickson é uma avaliação muito importante e tem sido muito utilizada, pois prediz a qualidade das mudas no viveiro, uma vez que engloba vários parâmetros morfológicos importantes para caracterizar a sobrevivência e a qualidade de mudas, dentre eles o cálculo de robustez e o equilíbrio da distribuição da biomassa da muda. Assim, este parâmetro demonstra o equilíbrio entre o desenvolvimento da parte aérea e do sistema radicular (MELO; CUNHA, 2008), que no presente estudo foi mais acentuado quando em substrato contendo terra, areia e cama de frango e maiores níveis de luminosidade (pleno sol e 30\% de sombra).

A utilização de substratos que contenham resíduos orgânicos com características adequadas à espécie plantada possibilita redução do tempo de cultivo e do consumo de insumos, defensivos e mão de obra (FERMINO; KAMPF, 2003). Estes resultados corroboram com os obtidos por Nóbrega et al. (2008), os quais avaliaram parâmetros morfológicos de mudas de angico (Anadenanthera peregrina) e sesbania (Sesbania virgata) cultivadas em substrato com compostos de lixo urbano. Os autores, também, observaram que a adição do composto orgânico no substrato ocasionou aumento no índice de qualidade de Dickson para ambas as espécies e ainda, em outras variáveis analisadas como a altura, relação massa seca de parte aérea por massa seca de raiz.

Em relação ao sombreamento, Melo e Cunha (2008) observaram que mudas de mulungu (Hancornia speciosa) cultivadas em pleno sol apresentaram maior IQD quando comparadas a 20, 4060 e $80 \%$, de sombreamento, assemelhando-se aos resultados obtidos neste trabalho.

Portanto, no presente estudo, observouse que mudas de Tocoyena formosa apresentam 
respostas variadas em relação ao sombreamento, de forma que se mostraram com potencial de adaptação à sombra com relação ao índice de clorofila. No entanto, o elevado nível de sombreamento limitou o crescimento das plantas e a capacidade de produção de biomassa. Dessa forma, o menor crescimento observado no ambiente sombreado sugere que essa condição foi limitante para o desenvolvimento da população testada.

O mesmo foi observado em relação ao tipo de substrato, em que o maior crescimento das mudas no substrato com cama de frango indica que este composto foi essencial para aumentar a qualidade das mudas. A presença da cama de frango, possivelmente, melhorou as características de aeração, estrutura e retenção de água, teor de matéria orgânica e quantidade de nutrientes, permitindo melhor desenvolvimento das mudas.

\section{CONCLUSÃO}

$\mathrm{O}$ crescimento e a qualidade das mudas de Tocoyena formosa são favorecidos pelo cultivo em pleno sol e $30 \%$ de sombreamento e no substrato terra + areia + cama de frango.

\section{AGRADECIMENTOS}

À CAPES pela concessão de bolsa de Mestrado à primeira autora.

\section{REFERÊNCIAS BIBLIOGRÁFICAS}

BERNARDINO, D. C. S. et al. Crescimento e qualidade de mudas de Anadenanthera macrocarpa Benth. Brenan em resposta à saturação por bases do substrato. Revista Árvore, Viçosa, v. 29, n. 6, p. 863-870, 2005.

COELHO, V. P. M.; AGRA, M. F.; BARBOSA, M. R.V. Estudo farmacobotânico das folhas de Tocoyena formosa (Cham. \&Schltdl.) K.Schum. (Rubiaceae).

Brazilian Journal of Pharmacognosy, Curitiba, v. 16, n. 2, p. 170-177, 2006.

CRITCHLEY, C. Molecular adaptation to irradiance: The dual functionality of photosystem II. In: SINGHAL, G. S. G.; RENGER, S. K.; SOPORY, K. D. Concepts in photobiology: photosynthesis and photomorphogenesis. Irrgang \& Govindjee, eds. Narosa.New Delhi: Publishing House, 1999. p. 573-587. DALE, J. E. The control of leaf expansion. Annual Review of Plant Physiology and Plant Molecular Biology, Palo Alto, v. 39, p. 267- 295, 1988.

DANTAS, B. F. et al. Taxas de crescimento de mudas de catingueira submetidas a diferentes substratos e sombreamentos. Revista Árvore, Viçosa, v. 33, n. 3, p. 413-423, 2009.

DICKSON, A.; LEAF, A. L.; HOSNER, J. F. Quality appraisal of white spruce and white pine seedling stock in nurseries. Forestry Chronicle, Ontário, v. 36, n. 1, p. 10-13, 1960.

EMBRAPA. Manual de métodos de análise de solo. 2. ed. Rio de Janeiro: Centro Nacional de Pesquisa de Solos, 1997. 212 p.

FACHINI, E.; GALBIATTI, J. A.; PAVANI, L. C. Níveis de irrigação e de compostos de lixo orgânico na formação de mudas em casa de vegetação. Engenharia Agrícola, Jaboticabal, v. 24, n. 3, p. 578-588, 2004.

FERMINO, M. H.; KAMPF, A. N. Uso do solo bom Jesus com condicionadores orgânicos como alternativa de substrato para plantas. Pesquisa Agropecuária Gaúcha, Porto Alegre, v. 9, n. 1-2, p. 33-41, 2003.

FERREIRA, D. F. Manual do sistema Sisvar para análises estatísticas. Lavras: Universidade Federal de Lavras, 2000. 63 p.

FERREIRA, W. N. et al. Crescimento inicial de Piptadenia stipulacea (Benth.) Ducke (Mimosaceae) e Anadenanthera colubrina (Vell.) Brenan var. cebil (Griseb.) Altshul (Mimosaceae) sob diferentes níveis de sombreamento. Acta Botanica Brasilica, São Paulo, v. 26, n. 2, p. 408-414, 2012.

FREITAS, G. A. et al. Influência do sombreamento na qualidade de mudas de Sclerolobium paniculatum Vogel para recuperação de área degradada. Journal of Biotechnology and Biodiversity, Gurupi, v. 3, n. 3, p. 5-12, 2012.

GOTTSBERGER, G.; EHRENDORFER, F. Hybrid speciation and radiation in the neotropical woody genus Tocoyena (Rubiaceae). Plant Systematics and Evolution, Austria, v. 181, n. 3-4, p. 143-169, 1992.

KÄMPF, A. N. Análise física de substratos para plantas. Viçosa: SBCS, 2001. v. 26, p. 5-7.

KIRKBY, E. A.; RÖMHELD, V. Micronutrientes na fisiologia de plantas: Funções, absorção e mobilidade. Encarte de informações agronômicas, n. 118, p. 1-24, 2007.

LARCHER, W. Ecofisiologia Vegetal. São Carlos: RIMA, 2006. $550 \mathrm{p}$.

LAVRES-JÚNIOR, J. et al. Deficiências de macronutrientes no estado nutricional da mamoeira cultivar Iris. Pesquisa Agropecuária Brasileira, 
Brasília, v. 40, n. 2, p. 145-151, 2005.

LIMA, J. D. et al. Efeitos da luminosidade no crescimento de mudas de Caesalpinia ferrea Mart. Ex Tul. (Leguminosae, Caesalpinoideae). Acta Amazônica, Manaus, v. 38, n. 1, p. 5-10, 2008. LUCA, E. F.; REBECCHI, R. J.; SCHORN, L. A. Crescimento e qualidade de mudas de cedro (Cedrela fissilis Vellozo) em viveiro, mediante diferentes técnicas de produção. Revista do Instituto Florestal, São Paulo, v. 22 n. 2, p. 189-199, 2010.

MATOS, F. S. et al. Influência da intensidade luminosa no desenvolvimento de mudas de Jatropha curcas L. Agrarian, Dourados, v. 4, n. 14, p. 265-272, 2011.

MELO, J. T. de. Respostas de mudas de espécies arbóreas do Cerrado a nutrientes em Latossolo Vermelho Escuro. Brasília, 1999. 104 f. Tese (Doutorado em Ecologia) - Universidade de Brasília, Brasília, 1999.

MELO, R. R.; CUNHA, M. C. L. Crescimento inicial de mudas de mulungu (Erythrina velutina Wild.) sob diferentes níveis de luminosidade. Ambiência, Guarapuava, v. 4, n. 1, p. 67- 77, 2008.

NAKAZONO, E. M. et al. Crescimento inicial de Euterpe edulis Mart. em diferentes regimes de luz. Revista Brasileira de Botânica, São Paulo, v. 24, n. 2, p. 173-179, 2001.

NÓBREGA, R. S. A. et al. Parâmetros morfológicos de mudas de Sesbania virgata (Caz.) Pers e de Anadenanthera peregrina (L.) cultivadas em substrato fertilizado com compostos de lixo urbano. Revista Árvore, Viçosa, v. 32, n. 3, p. 597-607, 2008.

PIEREZAN, L.; SCALON, S. de P. Q.; PEREIRA, Z. V. Emergência de Plântulas e crescimento de mudas de Jatobá com uso de bioestimulante e sombreamento. Cerne, Lavras, v. 18, n. 1, p. 127-133, 2012.

POTT, A. Pastagens das sub-regiões dos Paiaguás e da Nhecolândia do Pantanal Mato-grossense.
Corumbá: Embrapa, 1982. 49 p. (Circular Técnica, 10).

REGO, G.M.; POSSAMAI.Efeito do Sombreamento sobre o Teor de Clorofila e Crescimento Inicial do Jequitibá-rosa. Boletim de Pesquisa Florestal, Colombo, n. 53, p. 179-194, 2006.

RONDON-NETO, R. M. et al. Potencialidades de uso de espécies arbustivas e arbóreas em diferentes fisionomias de cerrado, em Lucas do Rio Verde/MT. Revista de Biologia e Ciências da Terra, Campina Grande, v. 10, n. 2, p. 113-126, 2010.

SANTIAGO, E. J. A. et al. Aspectos da anatomia foliar da pimenta-longa (Piper hispidinervium C.DC.) sob diferentes condições de luminosidade. Ciência e Agrotecnologia, Lavras, v. 25, n. 5, p. 1035-1042, 2001.

SEVERINO, L. S.; LIMA, R. L. S.; BELTRÃO, N. E. M. Composição Química de Onze Materiais Orgânicos Utilizados em Substratos para Produção de Mudas. Comunicado Técnico, Campina Grande, n. 278, p.1-5, 2006.

SCALON, S. P. Q. et al. Estresse hídrico no metabolismo e crescimento inicial de mudas de mutambo (Guazuma ulmifolia Lam.). Ciência Florestal, Santa Maria, v. 21, n. 4, p. 655-662, 2011. SOUZA, C. C. et al. Avaliação de métodos de determinação de água disponível e manejo da irrigação em solo roxa sob cultivo de algodoeiro herbáceo. Revista Brasileira de Engenharia Agrícola e Ambiental, Campina Grande, v. 4, n. 3, p. $338-342,2000$.

VIEIRA, J. F.; LIMA, L. C.; CAMPOS, R. M. Plano de Manejo da RPPN da Fazenda da Mata. 2010. 60 p. Disponível em: $<$ http://www.iap. pr.gov.br/arquivos/File/RPPN/Planos_de_Manejo/ PM_RPPN_FAZENDA_DA_MATA/Plano_de_ Manejo_RPPN_Fazenda_da_Mata.pdf $>$. Acesso em: 12 jan. 2013.

WALTERS, M. B.; REICH, P. B. Seed size, nitrogen supply, and growth rate affect tree seedling survival in deep shade. Ecology, Tempe, v. 81, n. 7, p. 1887-1901, 2000. 